\title{
GASTROINTESTINAL BLEEDING IN PATIENTS ADMITTED TO THE INTENSIVE CARE UNIT
}

\author{
Ruxandra OPRITA ${ }^{1,2} \bowtie$, Madalina ILIE ${ }^{1,2}$, Vasile SANDRU², Daniel BERCEANU², \\ Gabriel CONSTANTINESCU ${ }^{1,2}$
}

${ }^{1}$ University of Medicine and Pharmacy „Carol Davila“, Bucharest, Romania

${ }^{2}$ Gastroenterology Clinic, Clinical Emergency Hospital of Bucharest, Romania

\section{Abstract}

Introduction. Gastrointestinal bleeding is a life-threatening condition, with a mortality depending on the cause and severity.

The objective of this study was to retrospectively evaluate the epidemiological, clinical and evolutive aspects of a series of patients diagnosed with gastrointestinal bleeding, admitted to the Intensive Care Unit of the Clinical Emergency Hospital of Bucharest, Romania.

Material and methods. A retrospective, descriptive study was carried out, of patients diagnosed with upper and lower gastrointestinal bleeding, admitted to the Intensive Care Unit of the Clinical Emergency Hospital of Bucharest, Romania, between January $1^{\text {st }}$, 2013 - December 30th 2018 . The clinical variables were collected in a database designed exclusively for the study.

Results. We observed that most of the cases were bleedings situated above the Treitz's angle; the most frequent causes were peptic ulcer disease, followed by variceal hemorrhage and erosive gastroduodenitis. The three most frequent causes of upper gastrointestinal bleeding in our series were peptic ulcer disease, variceal hemorrhage and erosive gastroduodenitis. The global mortality due to gastrointestinal bleeding was

\section{Résumé}

L'hémorragie gastro-intestinale chez les patients admis à l'unité de soins intensifs

Introduction. L'hémorragie gastro-intestinale est une condition qui menace la vie du patient, ayant une mortalité qui dépend de sa cause et gravité.

L'objectif de l'étude a été d'évaluer de manière rétrospective les aspects épidémiologique, clinique et évolutif de toute une série de patients diagnostiqués avec hémorragie gastro-intestinale, admis à l'Unité de Soins Intensifs de l'Hôpital Clinique d'Urgence de Bucarest, Roumanie.

Matériel et méthodes. Nous avons fait une étude rétrospective et descriptive dans laquelle ont été analysées les histoires des patients diagnostiqués avec hémorragie gastro-intestinale supérieure et inférieure, admis à l'unité de Soins Intensifs de l'Hôpital Clinique d'Urgence de Bucarest, Roumanie, entre janvier $1^{\text {er }}$, 2013 et décembre 30, 2018. Les variables cliniques ont été rassemblées dans une base de données dédiée exclusivement à l'étude.

Résultats. Nous avons observé que la plupart des cas étaient des hémorragies situées au-dessus de l'angle de Treitz; les causes les plus fréquentes étaient l'ulcère peptique suivi de l'hémorragie variqueuse et la 
$9.8 \%$, with all cases occurring in the group of patients with upper gastrointestinal bleeding.

Conclusions. It should be noted that in the group of patients who died, all had hemorrhagic shock at the time of admission, a fact that occurred only in $23 \%$ of the cases who survived. This highlights the prognostic value of the hemorrhagic shock on admission.

Keywords: gastrointestinal bleeding, hemorrhage, intensive care unit, epidemiology, mortality.

\section{INTRODUCTION}

Gastrointestinal bleeding may originate in any segment of the digestive tract, from the esophagus to the anus. It can be upper or lower, as it occurs above or below the Treitz's angle. The relevance of this entity lies in its frequency and its close relationship with the morbidity and the mortality of the patients who suffer from it ${ }^{1,2}$.

Although the overall real incidence is not easy to determine, despite the large number of reports found in the medical literature, several population studies estimate an annual rate of 100 to 160 episodes per 100,000 inhabitants per year, being more frequent in the male and elderly population (prevalence increases with age) ${ }^{3}$.

Mortality of gastrointestinal bleeding depends on the cause and severity of the bleeding, the patient's coexisting comorbidities and the speed of the diagnostic and therapeutic approach. In general terms, the mortality associated with upper gastrointestinal bleeding (UGIB) ranges from $5 \%$ to $10 \%$, although it can reach $30 \%$ when it is secondary to esophageal varices ${ }^{3}$. Unlike this, the mortality of acute lower gastrointestinal bleeding (LGIB) is less dramatic, reaching $2.5 \%$, although this rate increases drastically to $23 \%$ when it develops during hospitalization ${ }^{4,5}$.

Although acute anemia represents the common finding in both UGIB and LGIB, the clinical presentation typically varies, according to the site of the bleeding lesion. Hematemesis and melena are characteristic for UGIB, while hematochezia is the most common semeiotic finding of LGIB. It should be noted that hematochezia can be an expression of UGIB, when the intestinal peristalsis is increased by the sudden irruption of blood in the small intestine, as well as melena can be an expression of bleeding below the Treitz's angle, when peristalsis is reduced. gastro-duodénite érosive. Les trois causes les plus fréquentes de l'hémorragie gastro-intestinale supérieure dans notre série ont été la maladie ulcéreuse, l'hémorragie variqueuse et la gastro-duodénite érosive. La mortalité totale due à l'hémorragie gastro-intestinale a été de 9,8\%, tous les cas survenant dans le groupe de patients avec hémorragie gastro-intestinale supérieure. Conclusions. Il est à remarquer que dans le groupe de patients qui sont décédés, tous ont subi un choc hémorragique à l'admission, fait produit chez seulement $23 \%$ des patients qui ont survécu. Cela souligne la valeur de ce signe clinique.

Mots-clefs: hémorragie gastro-intestinale, hémorragie, unité de soins intensifs, épidémiologie, mortalité.

Hemodynamic instability is more common in UGIB than in LGIB (30\% vs. $10 \%)^{4}$.

By taking into account the etiology and management (diagnostic approach and treatment) of upper gastrointestinal bleeding, it can be divided into "non-variceal UGIB“ (80 to $90 \%$ ) and „variceal UGIB" $(10-20 \%)^{3}$. The most important causes in the first group are peptic ulcer disease (60\%) (Figure 1), erosive gastroduodenitis (12\%) and Mallory-Weiss syndrome (4-6\%), while in the second group the only cause is bleeding due to varices (esophageal or gastric) $^{6,7}$ (Figure 2).

On the other hand, the causes of LGIB vary, according to the reports. The two most frequent causes of lower digestive hemorrhage are diverticular hemorrhage (15-40\%) and vascular malformations or angiodysplasia (2-30\%), followed by colitis of various causes $(10-20 \%)$, colonic neoplasia (10-15\%) and less frequently, small bowel bleeding $(2-9 \%)^{8,9}$.

Despite the advances in diagnostic techniques, in up to $12 \%$ of gastrointestinal bleeding cases a source cannot be identified.

The OBJective OF THE STUDY was to retrospectively evaluate the epidemiological, clinical and evolutive data of a series of patients diagnosed with gastrointestinal bleeding admitted to the Intensive Care Unit (ICU) of the Clinical Emergency Hospital of Bucharest, Romania.

\section{Materials AND METHOdS}

A retrospective, descriptive study was carried out, in which the clinical data of patients diagnosed with upper and lower gastrointestinal bleeding, admitted to the ICU of the Clinical Emergency Hospital of Bucharest, Romania, between January 1 ${ }^{\text {st }}, 2013$ to December $30^{\text {th }}, 2018$, were analyzed. The clinical 


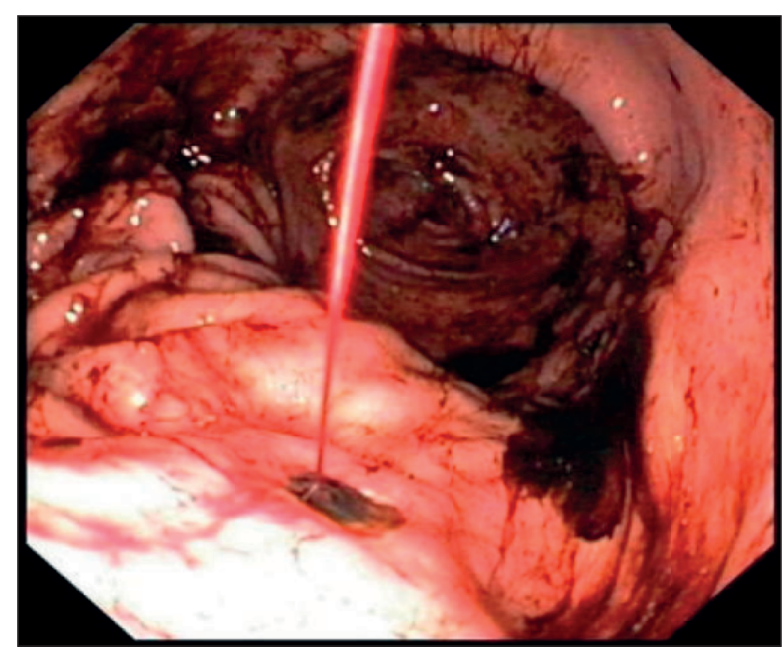

Figure 1. Gastric ulcer Forrest IA (endoscopy)

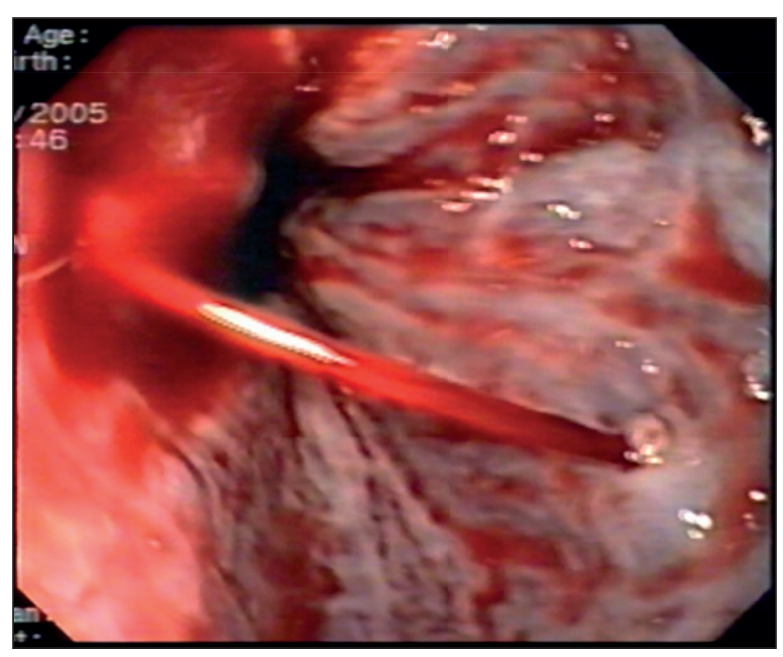

Figure 2. Active variceal bleeding (endoscopy) variables were collected in a database designed exclusively for the study. We excluded those patients in whom the pre-established clinical data could not be collected (demographic, clinical, absence of endoscopic studies).

The data obtained from the medical records were: age, sex, number of days of hospitalization in the ICU, personal history of hypertension (previous medical diagnosis or use of antihypertensive treatment), diabetes mellitus (previous medical diagnosis, at least two measurements of basal glycemia greater than $126 \mathrm{mg} / \mathrm{dL}$, use of antidiabetic medication), atrial fibrillation (previous or detected during admission), established coronary disease (previous acute coronary syndrome, stable angina pectoris, myocardial revascularization surgery), heart failure with reduced ejection fraction ( $<55 \%)$, chronic renal failure, intake of nonsteroidal anti-inflammatory drugs (NSAIDs) in the past 3 months, alcoholism (alcohol consumption greater than $60 \mathrm{~g} /$ day), cirrhosis (previous diagnosis or diagnosed during hospitalization), previous digestive hemorrhage, type of clinical presentation (hematemesis, melena, hematochezia, acute anemia, hypovolemic hemorrhagic shock, necessity of tranfusion of blood products), location of digestive bleeding (upper or lower), etiology (gastric ulcer, duodenal ulcer, erosive gastritis, duodenitis, gastric polyp, gastric cancer, Mallory-Weiss syndrome, esophageal varices, colonic angiodysplasia, diverticular hemorrhage, colon cancer, colorectal polyp), endoscopic study performed, surgical treatment, use of Sengstaken Blakemore tube, medical treatment and mortality.

For the description of the continuous variables, the mean and standard deviations were used, when the distribution was normal, and the median and the rank of percentiles otherwise (the normality of a variable was verified by the Kolmogorov-Smirnov test). The categorical variables were described by percentages. The bivariate comparison of groups was carried out with the Student t-tests (normal continuous variables), U-Mann-Whitney (continuous non-normal variables) and $\chi 2$ (categorical variables). A p <0.05 was considered as statistically significant in all the tests. For the analysis of data, we used the statistical program SPSS 25.0.0.0.

\section{Results}

Initially, the clinical data of 685 patients admitted with a diagnosis of gastrointestinal hemorrhage have been analyzed, from whom 75 cases were not eligible, based on the pre-established exclusion criteria: in 55 cases, no endoscopy was performed (in $32 \mathrm{pa}$ tients an endoscopy was not performed because they were not considered an emergency, 11 patients had isolated clinical signs of digestive hemorrhage in the context of another clinical picture, 9 patients refused to perform it and 3 deaths were registered within the first two hours of admission to ICU); 20 cases with a main diagnosis of gastrointestinal bleeding did not have a medical history that could be found in the hospital archives.

Of the 610 remaining cases, $455(74.6 \%)$ were men and 155 (25.4\%) women. The average age was 58.35 years, with a standard deviation of 18.27 . When performing the descriptive analysis of baseline characteristics, we found that $34 \%$ had a history of previous digestive bleeding, 28\% had consumed NSAIDs, $25 \%$ had terminal liver disease (cirrhosis) and $20.5 \%$ had therapeutic anticoagulation with acenocumarol ( $93 \%$ for atrial fibrillation). Other comorbidities have been diabetes mellitus type 2 (23.4\%), heart failure 
Table 1. Demographic characteristics and personal history of patients with gastrointestinal bleeding

\begin{tabular}{|c|c|}
\hline \multicolumn{2}{|c|}{ Demographic data } \\
\hline Male gender & $455(74.6 \%)$ \\
\hline Age & $58.35 \pm 18.27$ \\
\hline \multicolumn{2}{|c|}{ Medical history } \\
\hline Diabetes mellitus & $23.4 \%$ \\
\hline Heart failure & $14.6 \%$ \\
\hline Renal failure & $3.8 \%$ \\
\hline Cirrhosis & $25 \%$ \\
\hline Atrial fibrillation & $19 \%$ \\
\hline Anticoagulant therapy & $20.5 \%$ \\
\hline NSAIDs consumption & $28 \%$ \\
\hline $\begin{array}{c}\text { Previous gastrointestinal } \\
\text { bleeding }\end{array}$ & $34 \%$ \\
\hline $\begin{array}{l}\text { Chronic obstructive pulmo- } \\
\text { nary disease (COPD) }\end{array}$ & $1.3 \%$ \\
\hline
\end{tabular}

(14.6\%), chronic renal failure (3.8\%) and chronic obstructive pulmonary disease (1.3\%). Table 1 shows the baseline characteristics of the patients.

In relation to the clinical presentation of gastrointestinal bleeding, melena, acute anemia and hematemesis were the most common manifestations (78.4\%, $72 \%$ and $58.1 \%$, respectively), followed by hematochezia (47\%). 38\% presented with hemodynamic instability (hypovolemic / hemorrhagic shock).

Regarding the site of digestive bleeding, $87.53 \%$ were UGIB ( $\mathrm{n}=534), 12.47 \%$ were LGIB $(\mathrm{n}=76)$. Of all the cases of UGIB, 381 episodes were „non variceal“ $(71.3 \%)$ and 153 cases were „UGIB of variceal origin“ (28.7\%).

The total causes of gastrointestinal bleeding were: duodenal ulcer (26\%), gastric ulcer (21.1\%), esophageal or gastric varices (26\%), erosive gastritis (10.6\%), Mallory Weiss syndrome (2.4\%), duodenitis (1.6\%), and gastric polyps (0.8\%). Among the etiologies of LGIB, we found diverticular hemorrhage (4.9\%), colonic angiodysplasia (3.3\%), and colon cancer (0.8\%). Table 2 shows the causes determined in our study.

$66.8 \%$ of patients received endoscopic treatment with adrenaline injection, electrocoagulation with Gold Probe, application of hemoclips or elastic bands (depending on the cause), while $33.2 \%$ required only medical support (iv perfusion, transfusions of blood products, intense acid suppression etc). $11.4 \%$ of patients required surgical treatment of the bleeding, and in $6.9 \%$ of the cases the placement of a Sengstaken Blakemore tube was necessary.

The overall mortality due to digestive hemorrhage in our study was $9.8 \%$ (60 patients). All deaths
Table 2. Causes of digestive hemorrhage

\begin{tabular}{cc}
\hline \multicolumn{2}{c}{ Upper gastrointestinal bleeding } \\
\hline Peptic ulcer & $47.1 \%$ \\
\hline Duodenal ulcer & $26 \%$ \\
\hline Gastric ulcer & $21.1 \%$ \\
\hline Esophageal / gastric varices & $26 \%$ \\
\hline Erosive gastroduodenitis & $12.2 \%$ \\
\hline Erosive gastritis & $10.6 \%$ \\
\hline Duodenitis & $1.6 \%$ \\
\hline Mallory Weiss syndrome & $2.4 \%$ \\
\hline Gastric polyps & $0.8 \%$ \\
\hline Lower gastrointestinal bleeding \\
\hline Diverticular bleeding & $4.9 \%$ \\
\hline Colonic angiodysplasia & $3.3 \%$ \\
\hline Colorectal cancer & $0.8 \%$ \\
\hline Colorectal polyps & $0.8 \%$ \\
\hline $\begin{array}{c}\text { Gastrointestinal bleeding } \\
\text { from the small intestine }\end{array}$ & $1.63 \%$ \\
\hline
\end{tabular}

occurred in the UGIB group, so mortality in this population was $11.23 \%$. The two most frequent causes of death were variceal hemorrhage (45 patients) and duodenal ulcer (15 patients).

When performing the univariate analysis, we found that in the group of patients who died, hemorrhagic shock was detected more frequently at the time of admission $(100 \%$ of the patients who died compared to $28.2 \%$ of those who did not present this outcome; $p$ <.0001); at the same time, they received more frequently treatment with the Blakemore balloon catheter due to incoercible hemorrhage (23.1 versus $3.6 \%$ of patients who survived, $\mathrm{p}<0.0001$ ). Although the differences did not reach statistical significance in the rest of the variables analyzed, in the group of patients who died, a history of cirrhosis was more common (38.5\% versus $28 \%$ among those who did not die), the cause of variceal bleeding (38.5\% vs. $24.5 \%)$ and duodenal ulcer disease (38.5\% vs. $24.5 \%)$, expression of the gastrointestinal bleeding in the form of hematemesis $(76.8 \%$ vs. $51.8 \%$ ), the age over 65 years (61.5\% versus $47.3 \%$ ), and finally, the percentage of endoscopic treatment (61.5\% versus $45 \%)$. There were no differences related to age (in quantitative terms), sex, other antecedents, causes of bleeding and treatments performed.

\section{Discussion}

In our series of patients hospitalized for digestive hemorrhage, we observed that most of the episodes were above the Treitz's angle; the most frequent causes were peptic ulcer disease, followed by variceal 


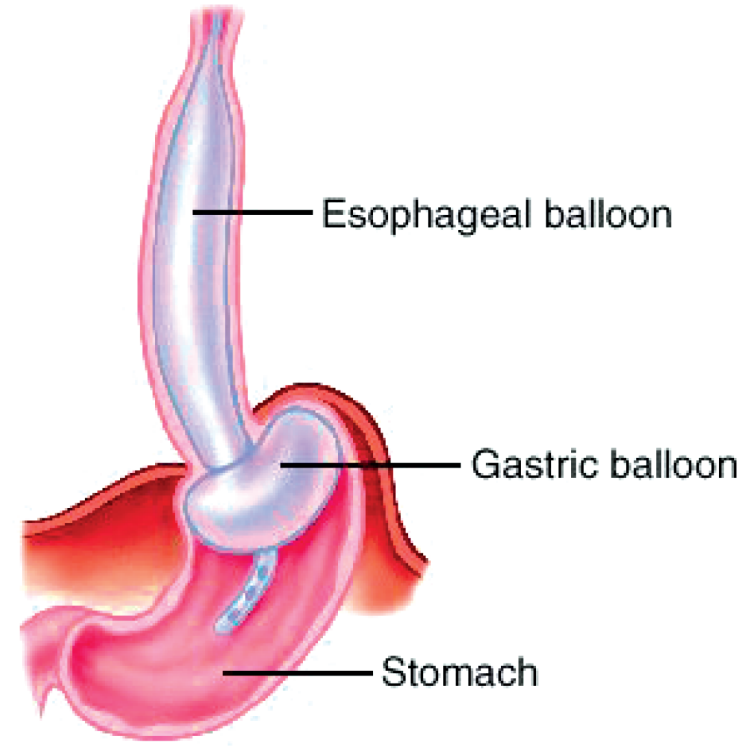

Figure 3. Sengstaken Blakemore tube

hemorrhage and erosive gastroduodenitis, and finally, in the group of patients who died, clinical presentation in the form of hemorrhagic shock and the need to use the Sengstaken Blakemore tube were more common (Figure 3).

The available reports on the frequency of bleeding origin (upper or lower) and its causes provide variable information, which probably reflects the trends over time of the different causes of gastrointestinal hemorrhage, the differences in the design of the studies, the populations studied (adults or elderly, patients admitted to surgical services or critical care etc), and type of diagnostic procedures performed ${ }^{10}$.

In our series of patients admitted for gastrointestinal bleeding, $87.53 \%$ of patients presented with UGIB. This contrasts with other studies, where the frequency of upper and lower gastrointestinal bleeding was similar; for example, in the work of Whelan et al, $51 \%$ of the cases presented as UGIB and the rest (49\%) had a lower source of bleeding ${ }^{11}$.

These differences can be justified mainly by the type of population studied. In our study, we evaluated patients admitted to an intensive care unit who are probably more severe $(38 \%$ of them presented hemorrhagic shock as a form of presentation) than in other series, where patients admitted to the general ward or only the endoscopic finding were taken into account.

The three most frequent causes of UGIB in our series were peptic ulcer disease (47.1\%, duodenal ulcer $26 \%$ and gastric ulcer $21.1 \%$ ), variceal hemorrhage (26\%) and erosive gastroduodenitis (12.2\%). Other causes were Mallory Weiss syndrome (2.4\%) and gastric polyp bleeding $(0.8 \%)$.
In most publications, $80 \%$ to $90 \%$ of UGIB cases were of non-variceal origin, which differs from our findings, where the percentage of upper non-variceal bleeding reached $70 \%{ }^{1}$. These differences could be explained by the fact that our hospital admits a significant number of patients with end-stage liver disease and because these patients usually have greater hemodynamic impairment, which requires their admission in the ICU.

In agreement with the majority of studies regarding acute LGIB, in our study, the most frequent causes were diverticular hemorrhage and colonic angiodysplasia. Although the number of patients with this pathology was low, as it is a cohort of patients admitted to ICU and these, most of the time, are self-limiting, considering only LGIB, we observed that $50 \%$ were of diverticular colonic origin and $33 \%$ due to colonic angiodysplasia. These findings are similar to those of Ghassemi et al ${ }^{12}$.

In our study, global mortality due to gastrointestinal bleeding was $9.8 \%$, with all cases occurring in the group of patients with UGIB $(11.23 \%$ if we consider only this group). The mortality rate from digestive hemorrhage has been progressively decreasing during the last two decades, due to the better diagnostic and therapeutic approach of the disease $\mathrm{e}^{13-18}$.

In a comparative study of two cohorts of patients with UGIB (period 1983-1985 and 2002-2004), Loperfido et al showed that mortality by this entity decreased from $17.1 \%$ to $8.2 \%$, respective$1 y^{19}$. Currently, the mortality due to UGIB is estimated to be between $7 \%$ and $12 \%$, and may reach $30 \%$ or more in the case of hemorrhage due to esophageal varices (depending on the intensity of bleeding and/ or severity of the underlying liver disease, estimated by the Child-Pugh score) ${ }^{20}$.

In our study, mortality due to non-variceal UGIB was $10.38 \%$, similar to that published in the literature, while the death rate due to variceal UGIB was lower than this (15.6\%), perhaps due to the rapid availability of endoscopic treatment that exists in our institution, which is fundamental for the urgent therapeutic gesture. It should be noted that in the group of patients who died, all had hemorrhagic shock at the time of admission, a fact that occurred only in $23 \%$ of the cases who survived. This highlights the prognostic value of the hemorrhagic shock and the importance of adequate early resuscitation in the management of these patients ${ }^{21,22}$.

The LGIB mortality in the literature is 2.4 $3.9 \%{ }^{23,24}$. In our study, there were no deaths due to LGIB, perhaps because the number of patients was low, most of them had self-limiting bleeding, since no case of LGIB was admitted with hemodynamic decompensation. 
It should be noted that our study has some limitations, the main one being its retrospective nature. Because of the lack of availability of all the data in some patients, such as severity scores at the time of admission, initial response to hemodynamic resuscitation in unstable patients, aspects related to the limitation of the therapeutic effort, number and type of transfusions performed etc, we could not identify other factors that could have influenced the final outcome (mortality) $)^{25-29}$.

\section{Conclusions}

The aim of our study was to show the demographic characteristics, personal history, form of presentation, causes and mortality in a series of cases of digestive hemorrhage admitted to an Intensive Care Unit. Most of the hemorrhagic events were digestive bleedings above the Treitz's angle. The most frequent causes of upper gastrointestinal bleeding were gastroduodenal peptic ulcer disease, followed by variceal hemorrhage and erosive gastroduodenitis. Finally, all the patients who died (38\%) presented hemorrhagic shock upon admission, which highlights its prognostic value.

\section{Compliance with Ethics Requirements:}

„The authors declare no conflict of interest regarding this article"

"The authors declare that all the procedures and experiments of this study respect the ethical standards in the Helsinki Declaration of 1975, as revised in 2008(5), as well as the national law."

"No funding for this study"

\section{References}

1. Kim BSM, Li BT, Engel A, et al. Diagnosis of gastrointestinal bleeding: A practical guide for clinicians. World Journal of Gastrointestinal Pathophysiology 2014;5(4):467-478.

2. Midgley RC, Cantor D. Upper gastrointestinal hemorrhagediagnosis and management. Western Journal of Medicine 1977; 127(5):371-377.

3. Chen Y-C, Hsiao C-T, Lin L-C, Hsiao K-Y, Hung M-S. The association between red blood cell transfusion and outcomes in patients with upper gastrointestinal bleeding. Clinical and Translational Gastroenterology 2018; 9(3):138.

4. El-Tawil AM. Trends on gastrointestinal bleeding and mortality: Where are we standing? World Journal of Gastroenterology 2012; 18(11):1154-1158.

5. Beck DE, Margolin DA, Whitlow CB, Hammond KL. Evaluation and management of gastrointestinal bleeding. The Ochsner Journal 2007; 7(3):107-113.

6. Strate LL, Gralnek IM. Management of patients with acute lower gastrointestinal bleeding. The American Journal of Gastroenterology 2016; 111(4):459-474.

7. Haq I, Tripathi D. Recent advances in the management of variceal bleeding. Gastroenterology Report 2017; 5(2):113-126.
8. Hreinsson JP, Kalaitzakis E, Gudmundsson S, Björnsson ES. Upper gastrointestinal bleeding: incidence, etiology and outcomes in a population-based setting. Scandinavian Journal of Gastroenterology 2013; 48(4):439-447.

9. Navuluri R, Kang L, Patel J, Van Ha T. Acute lower gastrointestinal bleeding. Seminars in Interventional Radiology 2012; 29(3):178-186.

10. Masoodi M, Saberifiroozi M. Etiology and outcome of acute gastrointestinal bleeding in Iran: a review article. Middle East Journal of Digestive Diseases 2012; 4(4):193-198.

11. Whelan CT, Chen C, Kaboli P, Siddique J, Prochaska M, Meltzer DO. Upper versus lower gastrointestinal bleeding: a direct comparison of clinical presentation, outcomes, and resource utilization. Journal of Hospital Medicine 2010; 5(3):141-147.

12. Ghassemi KA, Jensen DM. Lower gastrointestinal bleeding: epidemiology and management. Current Gastroenterology Reports 2013; 15(7):10.

13. Wilcox CM, Cryer BL, Henk HJ, Zarotsky V, Zlateva G. Mortality associated with gastrointestinal bleeding events: Comparing short-term clinical outcomes of patients hospitalized for upper GI bleeding and acute myocardial infarction in a US managed care setting. Clinical and Experimental Gastroenterology 2009; 2:21-30.

14. Bumbu A, Pasca B, Tit DM, Bungau S, Bumbu G. The effects of soy isoflavones and hormonal replacing therapy on the incidence and evolution of postmenopausal female urinary incontinence. Farmacia 2016;64(3):419-422.

15. Diaconescu D, Pantea Stoian A, Socea LI, et al. Hepatorenal syndrome: a review. Arch Balk Med Union 2018;53(2): 239-245.

16. Mogoanta SS, Costache A, Mutiu G, et al. A nonfunctional neuroendocrine tumor of the pancreas - a case report. Rom J Morphol Embriol 2015; 56(2 Suppl.):511-519.

17. Pallag A, Rosca E, Tit DM, Mutiu G, Bungau SG, Pop OL. Monitoring the effects of treatment in colon cancer cells using immunohistochemical and histoenzymatic techniques. Rom J Morphol Embriol 2015;56(3):1103-1109.

18. Stanimir M, Chiutu LC, Wese S, Milulescu A, Nemes RN, Bratu O. Mullerianosis of the urinary bladder: a rare case report and review of the literature. Rom J Morphol Embriol 2016;57(Suppl 2): 849-852.

19. Loperfido S, Baldo V, Piovesana E, et al. Changing trends in acute upper-GI bleeding: a population-based study. Gastrointestinal Endoscopy 2009; 70(2):212-224.

20. Kim YD, Cheon GJ, Kim MY, Suk KT, Baik SK, Kim DJ. Changes in the clinical outcomes of variceal bleeding in cirrhotic patients: a 10-year experience in Gangwon Province, South Korea. Gut and Liver 2012; 6(4):476-481.

21. Takeuchi N, Emori M, Yoshitani M, Soneda J, Takada M, Nomura Y. Gastrointestinal bleeding successfully treated using interventional radiology. Gastroenterology Research 2017; 10(4):259-267.

22. Chen ZJ, Freeman ML. Management of upper gastrointestinal bleeding emergencies: evidence-based medicine and practical considerations. World Journal of Emergency Medicine 2011; 2(1):5-12.

23. Speir EJ, Ermentrout RM, Martin JG. Management of acute lower gastrointestinal bleeding. Techniques in Vascular and Interventional Radiology 2017; 20(4): 258-262.

24. Monteiro S, Gonçalves TC, Magalhães J, Cotter J. Upper gastrointestinal bleeding risk scores: Who, when and why? World Journal of Gastrointestinal Pathophysiology 2016; 7(1):86-96. 
25. Schemmer P, Decker F, Dei-Anane G, et al. The vital threat of an upper gastrointestinal bleeding: Risk factor analysis of 121 consecutive patients. World Journal of Gastroenterology 2006; 12(22):3597-3601.

26. Diaconu CC, Dragoi CM, Bratu OG, et al. New approaches and perspectives for the pharmacological treatment of arterial hypertension. Farmacia 2018; 66(3):408-415.

27. Diaconu CC, Manea M, Iancu MA, et al. Hyponatremia in patients with heart failure: a prognostic marker. Rev Chim (Bucharest) 2018; 69(5):1071-1074
28. Diaconu CC, Stanescu AMA, Pantea Stoian A, et al. Hyperkalemia and cardiovascular diseases: new molecules for the treatment. Rev Chim (Bucharest) 2018; 69(6):1367-1370.

29. Stoicescu M, Csepento C, Mutiu G, Bungau S. The role of increased level of plasma renin in etiopathogenic arterial hypertension in the young. Rom J Morphol Embriol 2011;52(1 Suppl.):419-23. 